\title{
Mouse MafA, homologue of zebrafish somite Maf 1, contributes to the specific transcriptional activity through the insulin promoter
}

\author{
Miwako Kajihara, ${ }^{\mathrm{a}, \mathrm{d}}$ Hirohito Sone, ${ }^{\mathrm{b}}$ Michiyo Amemiya, ${ }^{\mathrm{b}}$ Yasutake Katoh, ${ }^{\mathrm{c}}$ \\ Masashi Isogai, ${ }^{a}$ Hitoshi Shimano, ${ }^{\mathrm{b}}$ Nobuhiro Yamada, ${ }^{\mathrm{b}}$ and Satoru Takahashi, ${ }^{\mathrm{a}, *}$ \\ a Institute of Basic Medical Sciences, University of Tsukuba, 1-1-1, Tennodai, Tsukuba 305-8575, Japan \\ ${ }^{\mathrm{b}}$ Department of Internal Medicine, University of Tsukuba, 1-1-1, Tennodai, Tsukuba 305-8575, Japan \\ ${ }^{c}$ Center for Tsukuba Advanced Research Alliance (TARA), University of Tsukuba, 1-1-1, Tennodai, Tsukuba 305-8575, Japan \\ d Bio-oriented Technology Research Advancement, Institution (BRAIN), 1-40-2, Nisshin-cho, Saitama-city, Saitama 331-8537, Japan
}

Received 20 October 2003

\begin{abstract}
Large Maf transcription factors, which are members of the basic leucine zipper (b-Zip) superfamily, have been reported to be involved in embryonic development and cell differentiation. Previously, we isolated a novel zebrafish large Maf cDNA, somite Maf1 (SMaf1), which possesses transactivational activity within its $\mathrm{N}$-terminus domain. To elucidate SMaf1 function in mammals, we tried to isolate the mouse homologue of zebrafish SMaf1. We isolated the mouse homologue of zebrafish SMaf1, which is the same molecule as the recently reported MafA. MafA mRNA was detected in formed somites, head neural tube, and liver cells in the embryos. In the adult mouse, MafA transcript was amplified in the brain, lung, spleen, and kidney by RT-PCR. MafA mRNA was also detectable in $\beta$-cell line. Next, we analyzed the transcriptional activity of MafA using rat insulin promoters I and II (RIPI and II), since a part of RIP sequence was similar to the Maf recognition element (MARE) and MafA was expressed in pancreatic $\beta$-cells. MafA was able to activate transcription from RIPII, but not RIPI, in a dose dependent manner and the activity was dependent on RIPE3b/C1 sequences. In addition, the amount of MafA protein was regulated by glucose concentration. These results indicate that MafA is the homologue of zebrafish SMaf1 and acts as a transcriptional activator of the insulin gene promoter through the RIPE3b element.
\end{abstract}

(c) 2003 Published by Elsevier Inc.

Keywords: Maf; b-Zip; Transcription factor; Insulin

The Maf transcription factors are basic-leucine zipper (b-Zip) family proteins and are homologues of the $\mathrm{v}$-Maf oncoprotein, which was isolated as a transforming component of the avian musculoaponeurotic fibrosarcoma virus, AS42 [1,2]. Maf family proteins are divided into two subgroups, the large Maf and the small Maf proteins. The large Maf proteins, MafA/L-Maf/ SMaf1 [3-5], MafB [6], c-Maf [7], and Nrl [8], contain an acidic domain in their N-termini that acts as a transcriptional activation site. By contrast, the small Maf proteins, MafK, MafF [9], and MafG [10], lack such an acidic domain.

\footnotetext{
${ }^{*}$ Corresponding author. Fax: +81-298-53-6965.

E-mail address: satoruta@md.tsukuba.ac.jp (S. Takahashi).
}

Several experiments have demonstrated that the large Mafs are key factors involved in cellular differentiation. MafA/L-Maf/SMaf1 takes part in lens differentiation, induces crystallin expression in chicken embryos [4], and is expressed in the somite during zebrafish development [5]. The MafB member has been identified as the affected gene in mice carrying the kreisler $(k r)$ mutation [11], and the gene product is required for segmentation of the hindbrain by controlling Hoxb-3 expression [12]. In addition, MafB down-regulates the expression of the transferrin receptor and inhibits erythroid differentiation in myelomonocytic cells [13]. Furthermore, ENU induced kreisler mutant (kreisler ${ }^{\mathrm{ENU}}$ ) displayed inadequate podocyte development in the kidney and caused nephrosis [14]. It has been reported that c-Maf activates the transcription of L7 gene expression in developing 
Purkinje cells [15] and controls the tissue-specific expression of interleukin-4 (IL-4) in $\mathrm{CD}^{+} \mathrm{T}$ helper 2 cells [16]. In addition, severe defects occur in the lens fiber cells of $c$-maf gene knock-out mice [17] and mutation of the c-maf gene is the cause of abnormal human ocular development [18]. Nrl, the last member of the large Mafs, is well known as the gene responsible for human Retinitis Pigmentosa [19]. Nrl contributes to the maturation and establishment of neuronal cells [20] and regulates the expression of the rhodopsin gene in the retina [21]. This accumulated information indicates that the large Maf proteins play indispensable regulatory roles in cellular differentiation, morphogenesis, and several distinct developmental processes.

It has been reported that large Mafs bind to the target DNA sequence by their basic domain and form either homodimers or heterodimers with other Mafs, Jun, or Fos $[6,22,23]$ through their leucine-zipper domains. Maf dimers bind to TRE (TPA-responsive element)-type Maf recognition elements, T-MARE (TGCTGACTCAG CA), or CRE (cAMP-responsive element)-type MARE, C-MARE (TGCTGACGTCAGCA) [22,24]. The chicken L-Maf was shown to recognize the core site (TGCTGAC, -108 to -102 ) within the $\alpha \mathrm{CE} 2$ sequence (CTCCGCATTTCTGCTGACCAC, -119 to -99), which was defined as the lens-specific enhancer element in the chicken $\alpha A$-crystallin promoter [25]. The hoxb-3 $\mathrm{r} 5$ enhancer sequences (TGTCATCCCCCTAAGTCAG CAGTTAC and CCAAATTTGCAGACACCTACAT TCTTGGC) are recognized by MafB [12]. The mouse IL-4 promoter (CTCATTTTCCCTTCCTTTCAGC AACTTTAACTC) [16] is associated with c-Maf and the rhodopsin promoter (TGCTGATTCAGCA) is the target site of $\mathrm{Nrl}$ [26]. These known Maf target sequences are conserved at least half sequences of MARE, indicating that MARE is the adequate consensus sequence of Maf target elements in vivo.

We previously isolated novel large Mafs named SMaf1 and SMaf2 transcription factors [5], in addition to previously isolated $\mathrm{MafB} / \mathrm{Val}$ and c-Maf factors from zebrafish [27,28]. At the amino acid level, SMaf1 is classified as MafA/L-Maf-type large Maf. SMaf1 showed transcriptional activation activity and the mRNAs were detected in the paraxial mesoderm cells after somite boundary formation. Our investigation of zebrafish large Mafs indicated that SMafs might play important roles in somitogenesis. Very recently, it has been reported that human and mouse MafA are expressed in the pancreatic $\beta$ cells of the islet of Langerhans and are the potential regulators of insulin gene expression $[29,30]$. To elucidate the detailed function of MafA/L-Maf/SMaf1 in mammals, we isolated mouse MafA, the homologue of zebrafish SMaf1, and analyzed its expression profile. Furthermore, we analyzed the transcriptional activity of MafA from several insulin promoter constructs as compared with other large Mafs.
Our data indicate that MafA is the potential transcriptional regulator of the mammalian insulin gene.

\section{Materials and methods}

Isolation of the mouse homologue of zebrafish SMaf1. The coding sequence of the mouse homologue of zebrafish SMafl was amplified from genomic DNA extracted from the tail of C57BL/6J mouse, using sense (5'-TTCTCCGACGACCACCTG) and antisense (5'-CTTCTCG TA(C/T)TTCTCCTTG) oligonucleotide primers. These primers correspond to peptide sequences FSDDQL and KEKYEK, respectively, which are conserved between human EST (BE676631), chicken L-Maf and zebrafish SMaf1. Polymerase chain reaction was performed with 1 cycle at $94{ }^{\circ} \mathrm{C}$ for $2 \mathrm{~min}$, followed by 35 cycles at $94{ }^{\circ} \mathrm{C}$ for $30 \mathrm{~s}, 55^{\circ} \mathrm{C}$ for $30 \mathrm{~s}$ and $72^{\circ} \mathrm{C}$ for $30 \mathrm{~s}$, then 1 cycle at $72^{\circ} \mathrm{C}$ for $3 \mathrm{~min}$ in $20 \mu \mathrm{l}$ of reaction mixture. The PCR product was cloned into pCRII-TOPO vector (Invitrogen) and sequenced. The genomic and cDNA clones were isolated from a $129 / \mathrm{SvJ}$ genomic library (Stratagene) and $10.5 \mathrm{dpc}$ mouse embryo cDNA library (Stratagene), respectively, using the PCR fragment as probe. Approximately $8.64 \times 10^{5}$ genomic and $2.4 \times 10^{6}$ cDNA phages were screened, and positive clones were subcloned into pBluescript II SK+ vector (Stratagene), and then the nucleotide sequences were determined.

In situ hybridization. In situ hybridization was performed as described previously [31]. E12.5 mice embryos were fixed overnight in 4\% buffered paraformaldehyde (PFA) at $4{ }^{\circ} \mathrm{C}$. Following cryoprotection with $30 \%$ sucrose in PBS, $10 \mu \mathrm{m}$ sections were cut using a cryostat. They were treated with protease $\mathrm{K}$ and fixed with $4 \%$ PFA. After postfixation, the sections were hybridized with digoxigenin (DIG)labeled RNA probes $(50 \mathrm{ng} / \mathrm{ml})$ in hybridization solution $(50 \%$ formamide, $5 \times \mathrm{SSC}$, pH $4.5,1 \% \mathrm{SDS}, 50 \mu \mathrm{g} / \mathrm{ml}$ heparin, and $50 \mu \mathrm{g} / \mathrm{ml}$ yeast RNA) at $65^{\circ} \mathrm{C}$ for $16 \mathrm{~h}$. The samples were washed with $50 \%$ formamide, $5 \times \mathrm{SSC}$, and $1 \% \mathrm{SDS}$ at $65^{\circ} \mathrm{C}$ for $30 \mathrm{~min}$, and three times with $50 \%$ formamide, $2 \times \mathrm{SSC}$ at $65^{\circ} \mathrm{C}$ for $30 \mathrm{~min}$, and subsequently incubated with alkaline phosphatase-conjugated anti-digoxigenin antibody (Roche) at $4{ }^{\circ} \mathrm{C}$ overnight. After washing with Tris-buffered saline with $0.1 \%$ Tween 20 (TBST), hybridization signals were visualized using nitroblue tetrazolium and 5-bromo-4-chloro-3-indolyl phosphatase as chromogen. For in situ hybridization of sectioned mouse embryos, the probes corresponding to the b-Zip coding region (229-359 amino acid) of the mouse mafA gene were synthesized using T3 and T7 RNA polymerases with DIG-11-uridin-5'-triphosphate labeling kit (Roche).

RT-PCR analysis of MafA gene expression. The total RNAs of individual tissues, cultured cell-line, and transfected cells were extracted from adult C57BL/6J mouse (27 w), INS-1 cells, and NIH3T3 cells, respectively, using TRIzol Reagent (Invitrogen). After DNase treatment, $1 \mu \mathrm{g}$ of the total RNA was used for cDNA synthesis using SuperScript First-Strand Synthesis System (Invitrogen). Polymerase chain reaction was performed with 1 cycle at $94^{\circ} \mathrm{C}$ for $2 \mathrm{~min}$, followed by 50 cycles at $94^{\circ} \mathrm{C}$ for $30 \mathrm{~s}, 55^{\circ} \mathrm{C}$ for $30 \mathrm{~s}$ and $72^{\circ} \mathrm{C}$ for $30 \mathrm{~s}$, and then 1 cycle of $72^{\circ} \mathrm{C}$ for $3 \mathrm{~min}$ in $20 \mu \mathrm{l}$ of reaction mixture. The MafA cDNA fragments $(405 \mathrm{bp})$ were amplified using sense $\left(5^{\prime}\right.$-CACC ACGTGCGCTTGG) and antisense (5'-CAGAAAGAAGTCGGG TG) oligonucleotide primers.

Cell culture and transient transfection assay. MafA, MafB, and c-Maf cDNAs were subcloned into pEFX3-FLAG eukaryotic expression plasmid [4]. The constructs $\Delta \mathrm{MafA}, \Delta \mathrm{MafB}$, and $\Delta \mathrm{c}-\mathrm{Maf}$ encode amino acids 229-359 of mouse MafA, amino acids 207-323 of mouse MafB, and amino acids 252-370 of mouse c-Maf, respectively. The reporter plasmids, RIPII-251 (II-251), RIPII-126 (II-251), RIPII100 (II-251), RIPI-746 (I-746), and RIPI-135 (I-135), were amplified by PCR from rat genomic DNA and cloned into pGL2-Basic vector (Promega). Mutated RIPII-251 (mII-251) was synthesized from II-251 using a QuickChange Site-Directed Mutagenesis Kit (Stratagene). NIH3T3 cells were maintained in Dulbecco's modified Eagle's 
medium, supplemented with $10 \%$ fetal bovine serum. The cells were transfected by the lipofection method using FuGENE6 Transfection Regent (Roche) and then harvested at $48 \mathrm{~h}$ post-transfection. The luciferase assay was performed according to the supplier's protocol using the Dual-Luciferase Reporter Assay System (Promega). Transfection efficiencies were routinely normalized by the co-expressed Renilla reniformis luciferase activity, which was expressed by pRL-TK (Promega) expression plasmid.

Immunostaining and Immunoblotting. Immunostaining of cultured cells was carried out as previously described [4]. The cells were fixed and incubated with anti-FLAG M2 antibody (Kodak), and then with goat anti-mouse IgG FITC conjugated antibody (Zymed). As much as $10 \mu \mathrm{g} / \mathrm{ml}$ Hoechst (bisBENZIMIDE, Sigma) was added to final wash solution. Immunoblotting was performed as described previously [32]. Lysates of transfected NIH3T3 cells were generated with cell lysis buffer. For electrophoretic gel mobility shift assay (EMSA), Mafs or $\Delta$ Mafs were synthesized with TNT coupled reticulocyte lysate or TNT coupled wheat germ extract in vitro transcription/translation systems (Promega), respectively, using pEFX3-FLAG-Mafs and pEFX3FLAG- $\Delta$ Maf constructs. As much as $100 \mu \mathrm{g}$ of extract from NIH3T3 cells or $1 \mu \mathrm{l}$ of in vitro translated protein lysate was applied to SDSpolyacrylamide gel. To detect the immunoreactive proteins, we used horseradish peroxidase-conjugated anti-FLAG M2 (Sigma) and ECL blotting reagents (Amersham).

Electrophoretic gel mobility shift assay. Maf and truncated $\Delta \mathrm{Maf}$ proteins were synthesized with in vitro transcription/translation systems (Promega). RIPE3b and RIPE3b-I (RIPE3b of RIPI) oligonucleotides, (5'-GATCCGTTTGGAAACTGCAGCTTCAGCCCCA) and (5'-GATCCGTTTGGAAATTACAGCTTCAGCCCCA), corresponding to the RIP II $(-129$ to -105$)$ and the RIP I $(-141$ to -117$)$, respectively, were labeled with $\left[{ }^{32} \mathrm{P}-\alpha\right] \mathrm{dCTP}$ using Klenow DNApolymerase. An aliquot of $7 \mathrm{ml}$ of in vitro translated proteins was mixed with $2 \mathrm{ng}$ of a radiolabeled oligonucleotide in a reaction mixture containing $10 \mathrm{mM}$ Hepes- $\mathrm{KOH}(\mathrm{pH}$ 7.9), $100 \mathrm{mM} \mathrm{NaCl}, 2 \mathrm{mM}$ EDTA, $80 \mathrm{mM}$ DTT, and $50 \mu \mathrm{g} / \mathrm{ml}$ of poly (dI-dC), and analyzed by a $4 \%$ polyacrylamide gel in $0.25 \times$ TAE $(10 \mathrm{mM}$ Tris- $\mathrm{HCl}(\mathrm{pH} 8.0)$, $10 \mathrm{mM}$ acetate, and $0.25 \mathrm{mM}$ EDTA). The gels were dried up and exposed to X-ray films for $12 \mathrm{~h}$. In the competition assay, the EMSA reaction mixture was first incubated with a radiolabeled probe at $25^{\circ} \mathrm{C}$ for 15 min and then unlabeled RIPE3b, RIPE3b-I or mutated RIPE3b oligonucleotide (5'-GATCCGTTTGGAAACTCAGGCTTCAGCCC CA) was added to the reaction mixture.

\section{Results}

\section{Mouse MafA is a homologue of zebrafish SMaf1}

To isolate the mouse gene fragments homologous to zebrafish Smafl encoding the b-Zip domain, we performed PCR analysis using mouse genomic DNA and oligonucleotides corresponding to the conserved region of known SMaf1/L-Maf homologues (Fig. 1A). The resultant PCR products were subcloned and sequenced (Fig. 1B). Half of the clones encoded part of the basic and leucine-zipper domains of mouse SMaf1 homologue. The Smafl genomic DNA and cDNA were obtained by screening a mouse genomic library prepared from $129 \mathrm{~Sv}$ mice and a mouse cDNA library prepared from $10.5 \mathrm{dpc}$ CD1 mouse embryo, respectively, using the partial mouse SMafl clone as probe. In the result, we isolated a mouse SMaf1 genomic clone that is similar to the known large Maf sequences. And the cDNA clone implicated that this mouse SMafl gene is expressed in the mouse embryo.

Sequence analysis indicated this SMafl homologue clone as mouse MafA, which has been reported very recently [30]. The clone encodes a protein containing acidic, basic, and leucine zipper domains conserved
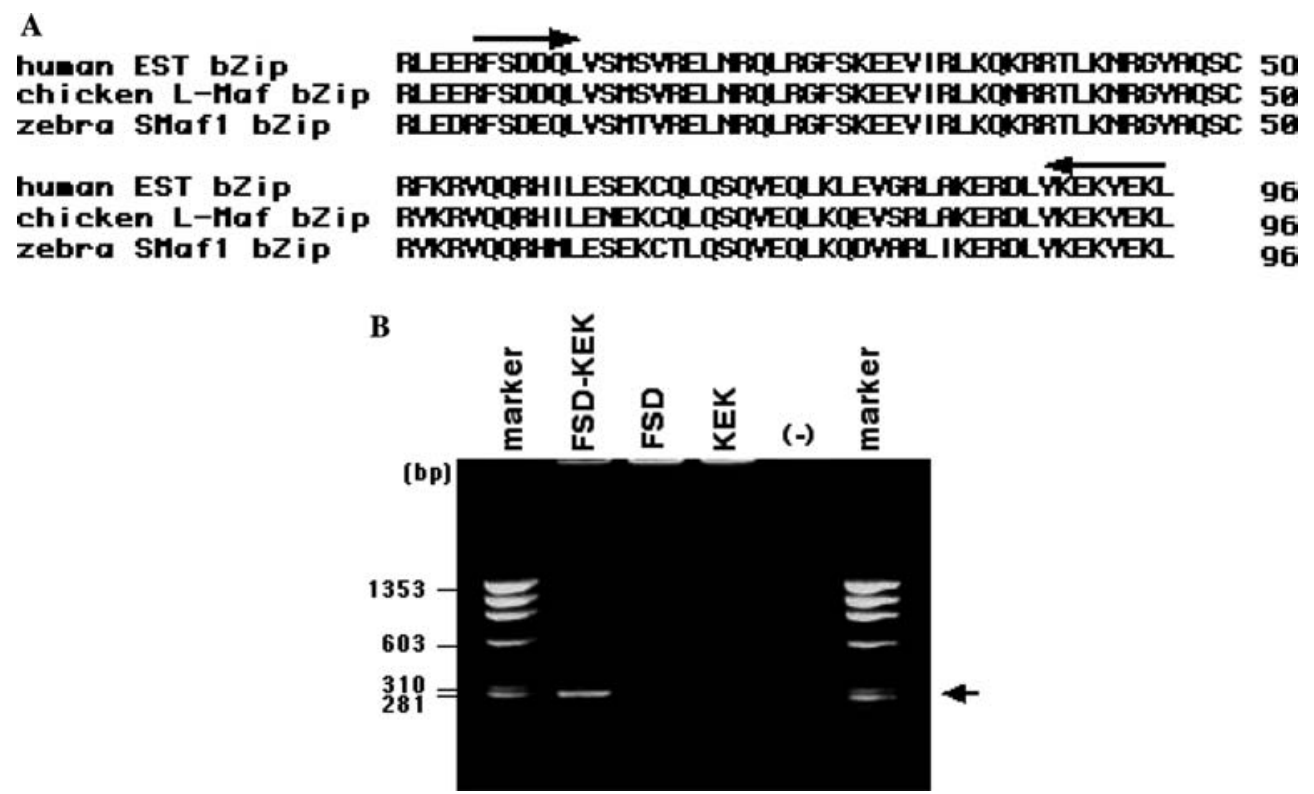

Fig. 1. The mouse homologue of zebrafish SMaf1 exists in the mouse genome. (A) Conserved amino acid sequences of known MafA/L-Maf/SMaf members. The human EST is the data of BE676631. The primer-set was constructed for the b-Zip sequence of L-Maf/SMaf members. Arrows depict the location of sense and antisense primers. (B) DNA fragments derived from mouse genomic mafA gene. FSD and KEK lanes show the PCR experiments with a single primer. The arrow indicates the expected PCR product. 


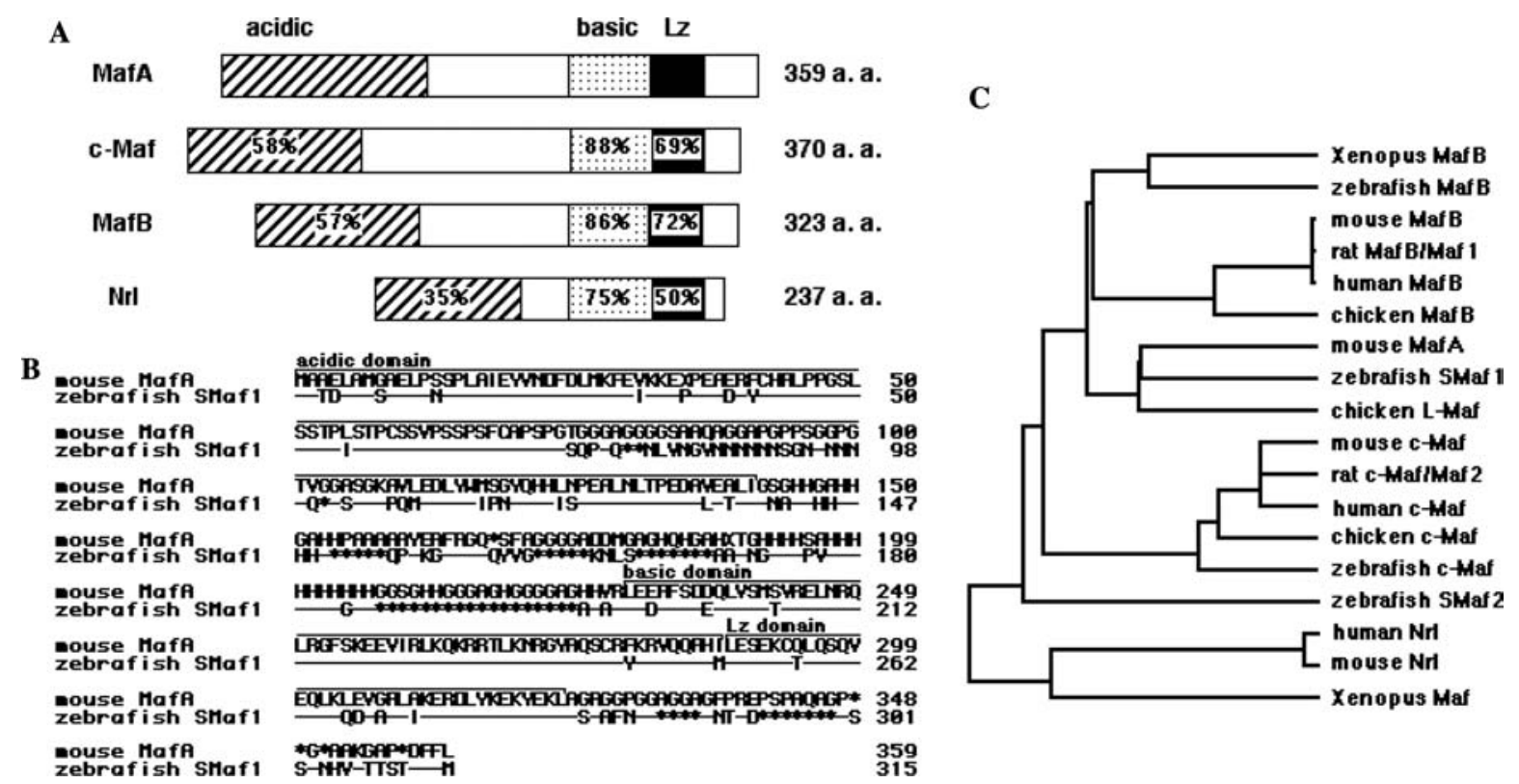

Fig. 2. Mouse MafA is a zebrafish SMaf1 homologue. (A) Schematic representation of MafA and other mouse large Mafs. Hatched boxes, acidic domains; gray-boxes, basic domains; and solid boxes, leucine zipper (Lz) domains. Percentages of amino acid sequences identical to MafA are indicated in each domain box. (B) Sequence alignment of mouse MafA and zebrafish SMaf1. Horizontal bars and asterisks represent identical amino acid residues to mouse MafA and gaps, respectively. The acidic, basic, and Lz domains are indicated. (C) Phylogenetic tree of vertebrate large Mafs. The tree was generated by the UPGMA method using the whole amino acid sequences of the known large Mafs.

amongst the large Maf subfamily, and its basic domain showed high homology $(>75 \%)$ to that of other mouse large Maf members (Fig. 2A). Mouse MafA cDNA shares $85 \%, 92 \%$, and $86 \%$ amino acid sequence identities with the individual acidic, basic and leucine zipper moieties, respectively, of zebrafish SMaf1 (Fig. 2B). A phylogenetic tree based on the entire amino acid sequences of each Maf protein (Fig. 2C) indicated that the isolated clone belongs to the chicken L-Maf/zebrafish SMaf1 class. According to these observations, we concluded that mouse MafA is a homologue of zebrafish SMaf1. Based on the sequence similarity, the amino acid sequence of mouse MafA is closer to that of zebrafish SMaf1 than that of chicken L-Maf (Fig. 2C).

\section{Expression of mouse MafA}

In order to analyze the spatial expression profile of mouse MafA during the fetal period $(12.5 \mathrm{dpc})$, we performed whole mount in situ hybridization using DIG-labeled probe (Fig. 3). MafA mRNA was detected in each formed somite and its expression pattern appeared to be in the myotomal cells (Fig. 3C arrows). The expression pattern of mouse MafA in the somite is similar to that of zebrafish SMaf1. MafA mRNAs were also observed in the head neural tube (Fig. 3E arrows) and liver cells (Fig. 3G arrows). A low level of MafA transcripts was detected in some mesenchyme-like cells.

Next, to reveal the expression of mouse MafA in the adult mouse, we performed RT-PCR using cDNA synthesized from adult C57BL/6J brain, thymus, heart, lung, liver, spleen, pancreas, trunk muscle, and kidney (Fig. 4A). We used pancreas cDNA at three times the volume of the others, in order to obtain equivalent amounts of control HPRT PCR product. In this experiment, the fragments derived from MafA mRNA were detected in the extracts of brain, lung, spleen, pancreas, and kidney. These PCR products were subcloned and the sequences were verified (data not shown). Mouse MafA transcripts were undetectable in the trunk muscle; a similar result was found for zebrafish SMaf1 mRNA, which diminishes as maturation proceeds in the somite cells.

Recently, it has been reported that MafA is a transcriptional activator of the human insulin gene [30]. To assess the expression of MafA in pancreatic $\beta$ cells, where insulin peptide hormone is produced, we tested RT-PCR using cDNA synthesized from the INS- 1 cells derived from mouse pancreatic $\beta$ cells (Fig. 4B). MafA transcripts were certainly detected in the cDNA of INS1 cells and also slightly recognized in the cDNA of NIH3T3 mouse fibroblast cells (data not shown).

\section{Large Mafs activate the rat insulin promoter II}

It is well known that mouse and rat have two insulin genes and that each gene has a specific expression profile [33-36]. To assess the contribution of large Mafs to the transactivation activity of the insulin gene through the rat insulin promoters I and II (RIPI and II), we first 

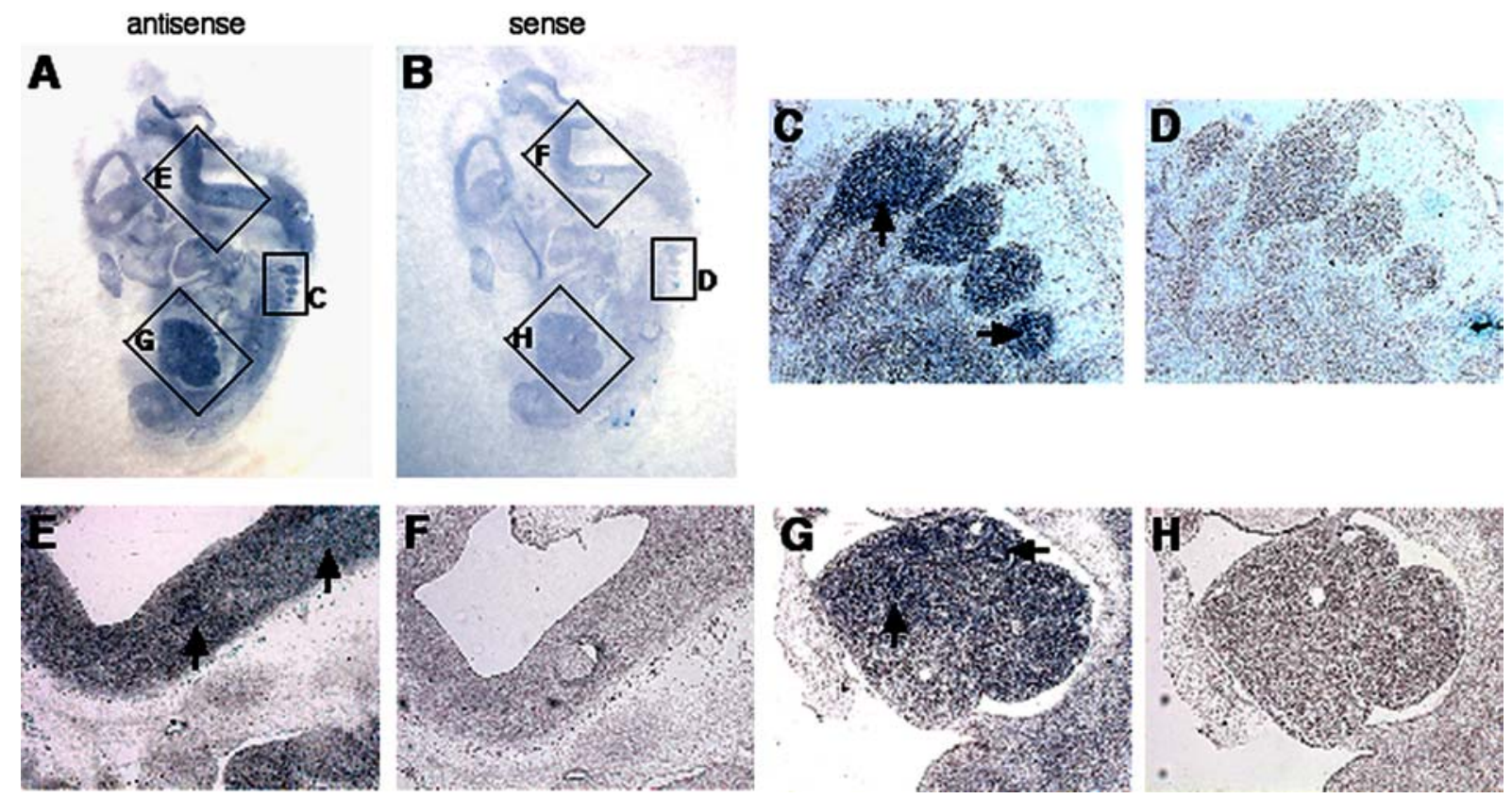

Fig. 3. Expression of Mouse MafA is detected in the mouse fetus. (A) The mouse MafA mRNA expression of longitudinal section with antisense probes. (B) This represents a sense probe control. (C,E,G) and (D,F,H) show higher magnifications of (A,B), respectively, and the frames exhibit each range. Expression of MafA in the somite cells $(C, D)$, the anterior neural tube cells $(E, F)$, and the liver cells $(\mathrm{G}, \mathrm{H})$. Each arrow indicates one of the stained cells. A $12.5 \mathrm{dpc}$ mouse fetus was used, sectioned laterally. Anterior to the top (A,B).

A

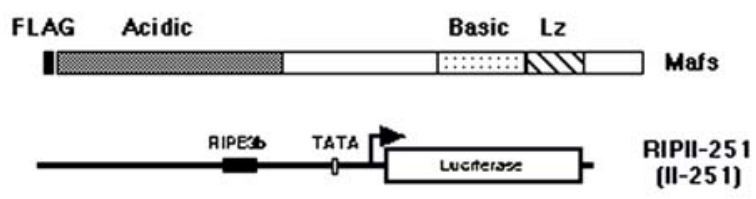

E

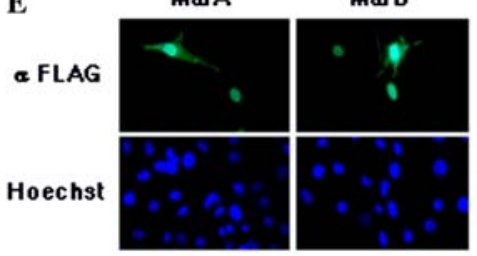

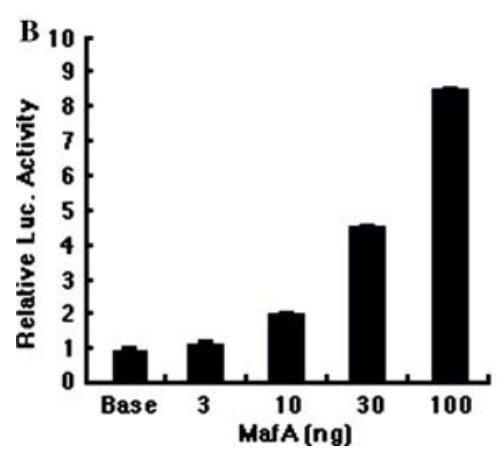
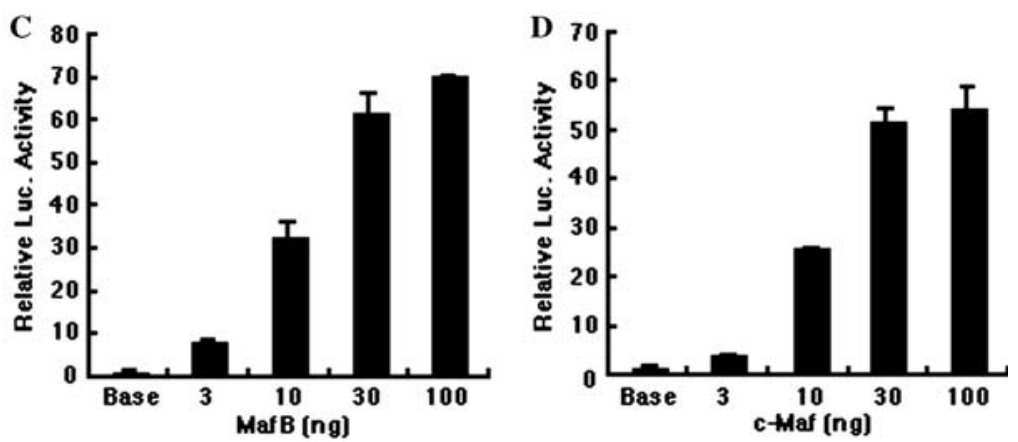

Fig. 5. Large Mafs activate reporter gene expression. (A) Schematic representation of the FLAG-Maf fusion protein and reporter construct (II-251). (B-D) Transactivation activity of large Maf proteins. Rat insulin promoter II (RIPII) reporter plasmid was transfected into NIH3T3 cells with each volume of Maf expression plasmids. (B-D) represent the result of MafA, MafB, and c-Maf, respectively. Luciferase activity in the absence of the effector plasmids was arbitrarily set at 1 and the mean values of triplicate samples are shown. (E) Detection of transfected Maf proteins in NIH3T3 cells by immunostaining. Transfected cells were incubated for $48 \mathrm{~h}$ and immunostained with an anti-FLAG Antibody (green). The nuclei were stained with Hoechst (blue).

analyzed the activities of MafA, MafB, and c-Maf in a co-transfection/transactivation assay using RIPII in NIH3T3 fibroblast cells. The effector Mafs were pre- pared as constructs with FLAG at the N-termini, while the reporter construct RIPII-251 (II-251) was cis-linked to a luciferase gene and contained the rat insulin 


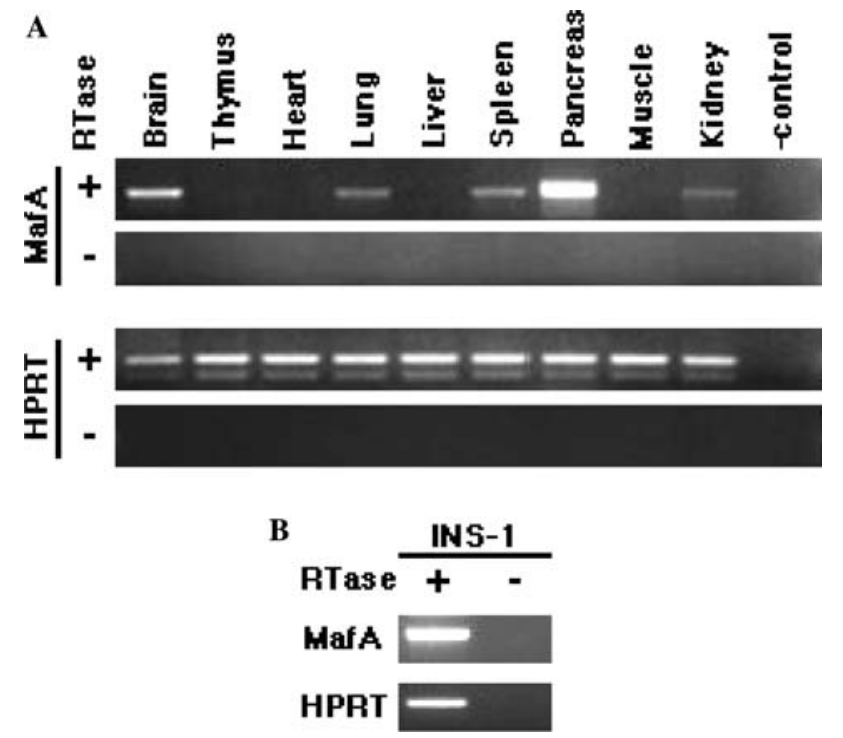

Fig. 4. MafA mRNA is expressed in various organs of adult mice. MafA mRNAs were detected in the cells of brain, lung, spleen, pancreas, kidney, and INS-1 cells (A,B; upper panels). HPRT was used as an internal control (A,B; lower panels). Reverse transcriptase (RTase)-samples were examined to expose DNA contamination of each RNA source.

promoter II ( -251 to -1$)$, including the RIPE3b element which is a putative Maf binding site (Fig. 5A). The transcriptional activity of MafA increased with an increasing transfection volume of effector (Fig. 5B). The transcriptional activities of MafB and c-Maf were six to seven times stronger than that of MafA (Fig. 5C). Taken together, these results indicate that the large Mafs possess transcriptional activity for the RIPII. Since c-Maf and MafB knock-out +/- mice did not show dysglycemia, whereas MafA knock-out +/- mouse showed exceptional sugar metabolism (our unpublished observation), further analysis was restricted to MafA and MafB was used as a positive control. To confirm the expression of transfected genes, we performed immunostaining of culture cells transfected with MafA or MafB using anti-FLAG antibody (Fig. 5E). The Maf proteins induced to cells were detected in the nucleus.

\section{RIPE3b is the target site of MafA and MafB}

To designate the site of MafA recognition, two reporter constructs were prepared. II-126 and II-100 contain $126 \mathrm{bp}(-126$ to -1$)$ and $100 \mathrm{bp}(-100$ to -1$)$ of RIPII, respectively (Fig. 6A). We also constructed $\Delta$ Mafs, where $\Delta$ MafA (amino acid 229-359) and $\Delta$ MafB (amino acid 207-323) lack acidic domains, in order to estimate the functional importance of the acidic domain for transactivation (Fig. 6B). The $\Delta$ Mafs were tagged with N-terminal FLAGs. Whereas MafA and MafB exhibited similar luciferase activities with II-251 and II126 reporters, II-100 was not activated by either Maf
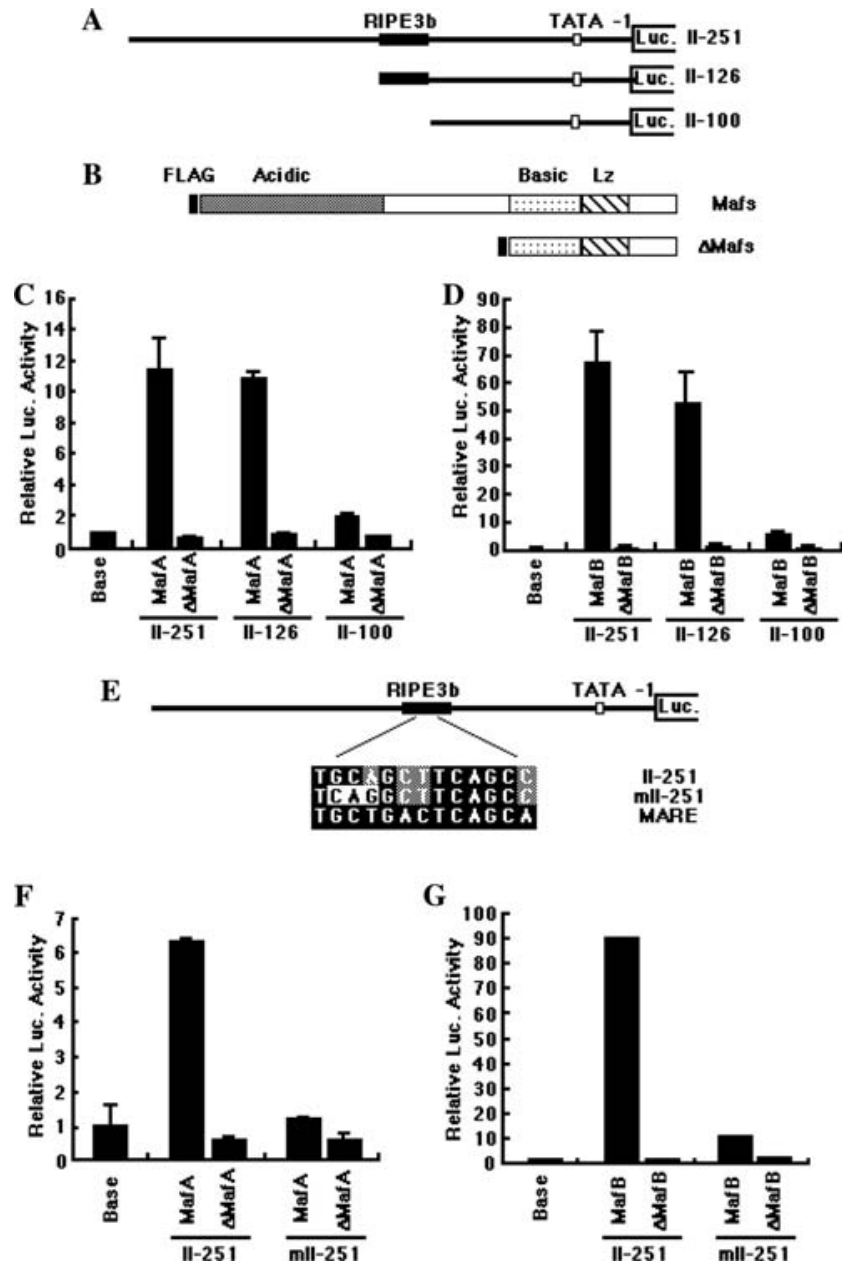

Fig. 6. The RIPE3b element is the target sequence of Mafs. (A) The $5^{\prime}$ end deletion reporters and (B) truncated Maf mutants are shown schematically. (C,D) Results of transient transfection assay using MafA and MafB effector, respectively. The large Maf proteins activated the expression of reporter constructs, II-251 and II-126, but not of II-100. (E) The mutant sequences of RIPII-251 reporter are shown compared with MARE motif. (F,G) The mII-251 reporter was not sufficiently activated with both MafA and MafB. (C-F) Both $\triangle$ MafA and $\triangle \mathrm{MafB}$, which lacked the acidic domains, did not cause obvious activation.

factor (Figs. 6C and D). These results indicate that the responsible elements for Maf activation are located between -126 and -101 of RIPII. Since this region includes the RIPE3b element, which contains the Maf recognition element (MARE) like sequence [22] (Fig. 6E), we focused on the core site $(-119$ to -113$)$ of the RIPE3b element as the Maf binding sequence. To elucidate the importance of the sequence, we constructed a mutated RIPE3b (mII-251) reporter based on the II-251 construct, whose mutation abolishes binding of Mafs [5] (Fig. 6E). When MafA or MafB was transfected with mII-251 reporter plasmid, the luciferase activity decreased by $90-95 \%$ (Figs. $6 \mathrm{~F}$ and G). These data indicated that the core sequence $(-119$ to -113$)$ of the RIPE3b element is the target site for Mafs, and the two 
nucleotides GC are crucial for transactivation of RIPII by Mafs. In addition, neither $\triangle$ MafA nor $\Delta$ MafB activated the transcription of the reporter in any of the experiments (Figs. 6C, D, F, and G). These results suggested that activation of MafA and MafB through the insulin promoter depends on acidic domain function.

\section{Maf $A$ and MafB specifically bind to the RIPE3b element}

To confirm that Mafs directly bind to the RIPE3b element, we carried out an electrophoresis gel mobility shift assay (EMSA) using RIPE3b oligonucleotide as probe. Maf and $\triangle$ Maf proteins were synthesized using in vitro systems and the proteins were confirmed by immunoblotting with FLAG epitope antibody (Fig. 7A). The results showed that all MafA (lane 3), MafB (lane 7), $\Delta$ MafA (lane 13), and $\triangle \mathrm{MafB}$ (lane 17) proteins could bind to the RIPE3b oligonucleotide (Figs. 7B and C). To examine the DNA binding specificity, unlabeled RIPE3b oligonucleotide or mRIPE3b oligonucleotide was added to the binding reaction as competitor. Addition of unlabeled RIPE3b oligonucleotide, but not mRIPE3b oligonucleotide, reduced the shifted DNA-protein complexes containing Maf or $\Delta$ Maf factors in each case. We concluded that MafA and MafB bind to RIPII and recognize the core site of RIPE3b specifically. Our results also demonstrated that the reduced activity observed using acidic domain deletion mutants is not due to a loss in DNA-binding (Figs. $6 \mathrm{C}, \mathrm{D}, \mathrm{F}$, and $\mathrm{G})$.

\section{MafA and MafB do not activate the RIPI}

There is a high similarity between the sequences of RIPI and RIPII. To assess the transcriptional activity of Maf factors with the RIPI, we carried out luciferase assays using an RIPI reporter (Fig. 8A). The luciferase activity of the RIPI (I-746) was not of an adequate level compared with that of RIPII (II-251) with either MafA or MafB (Figs. 8B and C). Further examination was carried out using I-135 reporter (Fig. 8A) to exclude the possibility that the I-746 construct contains negative regulatory elements. The transactivation activity of MafA or MafB was not detected for I-135 (Figs. 1B and C). Taken together, we concluded that both MafA and MafB could activate the RIPII, but not RIPI. The nucleotide difference in the core sequence of RIPE3b between RIPII and RIPI is a possible explanation for this. In the RIPE3b of RIPI (RIPE3b-I), the crucial nucleotide $\mathrm{G}$ required for recognition of Maf proteins (see Fig. 6) was substituted with A (Fig. 8D). To confirm this hypothesis, we did EMSA using RIPE3b-I and RIPE3b oligonucleotides as competitors. RIPE3b-I showed significantly less

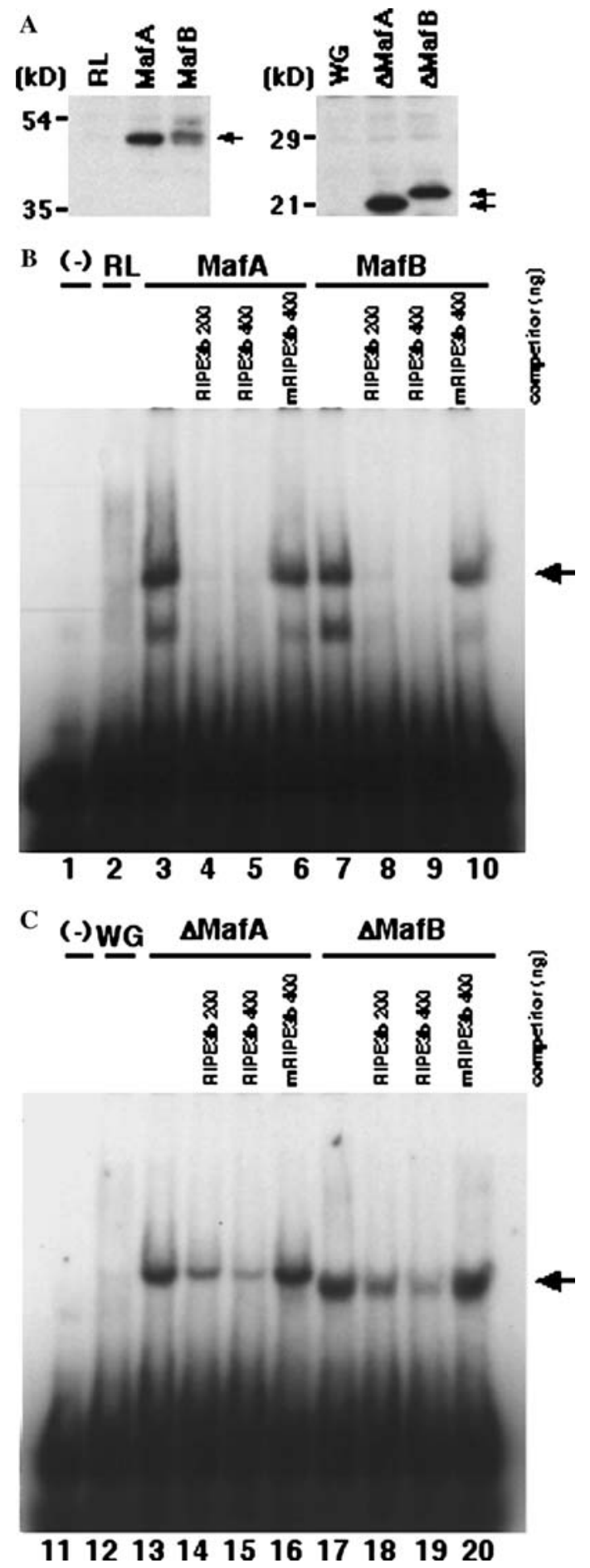

Fig. 7. MafA and MafB bind to RIPE3b. (A) Immunoblotting for the confirmation of Maf and $\Delta$ Maf proteins synthesized in vitro. (B,C) DNA binding activity of MafA and MafB (lanes 3-10) or $\triangle$ MafA and $\triangle$ MafB (lanes 13-20) was analyzed using RIPE3b oligonucleotides as probe. Lanes indicated as (-), RL or WG contained no proteins (lanes 1 and 11), the crude proteins in rabbit reticulocyte lysate (lane 2), and those in wheat germ extract (lane 12), respectively. We used 100- (lanes $4,8,14$, and 18) or 200- (lanes 5, 9, 15, and 19)-fold excess of RIPE3b oligonucleotides, or 200-fold excess of mRIPE3b oligonucleotides (lanes 6, 10, 16, and 20) as the unlabeled competitors. Arrows denote the positions of the DNAMafs complexes. 

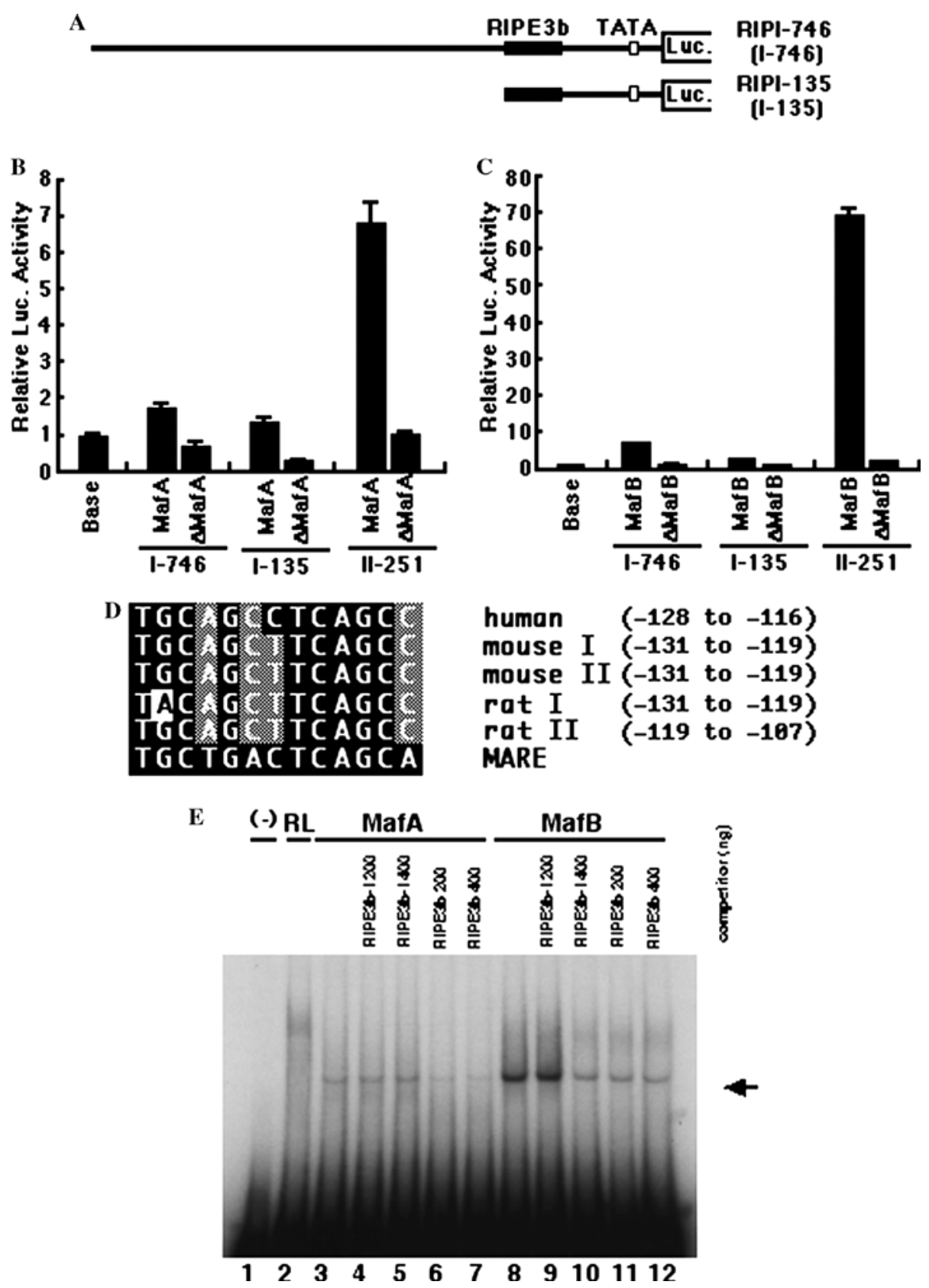

Fig. 8. Rat insulin promoter I (RIPI) reporter is not activated by Mafs. (A) Schematic representation of RIPI reporter constructs. (B,C) Mafs do not possess adequate transcriptional activity for RIPI. (D) Conservation of the nucleotide sequence of insulin promoters and MARE. Focus on the -130th nucleotide, "A," of RIPI. (E) DNA binding activity of MafA and MafB (lanes 3-12) was analyzed using RIPE3b oligonucleotides as probe. Lanes indicated as (-) and RL contained no proteins (lanes 1) and the crude proteins in rabbit reticulocyte lysate (lane 2), respectively. We used 100(lanes 4 and 9) or 200- (lanes 5 and 10)-fold excess of RIPE3b-I oligonucleotides (RIPE3b of RIPI), or 100- (lanes 6 and 11) or 200- (lanes 7 and 12)fold excess of RIPE3b oligonucleotides as the unlabeled competitors. Arrows denote the positions of the DNA-Mafs complexes.

competing activity as compared with RIPE3b (Fig. 8E). These data indicate that transcription from RIPI is not under large Maf regulation.

The amount of MafA protein increases by high glucose level

It has been shown that the transcriptional activity of MafA was lower than those of MafB and c-Maf (Figs.
5B-D). To confirm the expression of Maf proteins in transfected NIH3T3 cells, we performed immunoblotting and immunostaining of transfected NIH3T3 cells with anti-FLAG antibody. MafA protein was least detected as compared with other Mafs and $\Delta$ Mafs (Figs. 9A and C). To assess transcriptional level from transfected MafA plasmids, we carried out RT-PCR analysis (Fig. 9B). MafA transcripts were sufficiently expressed as well as $\Delta$ MafA. Since insulin expression was induced 


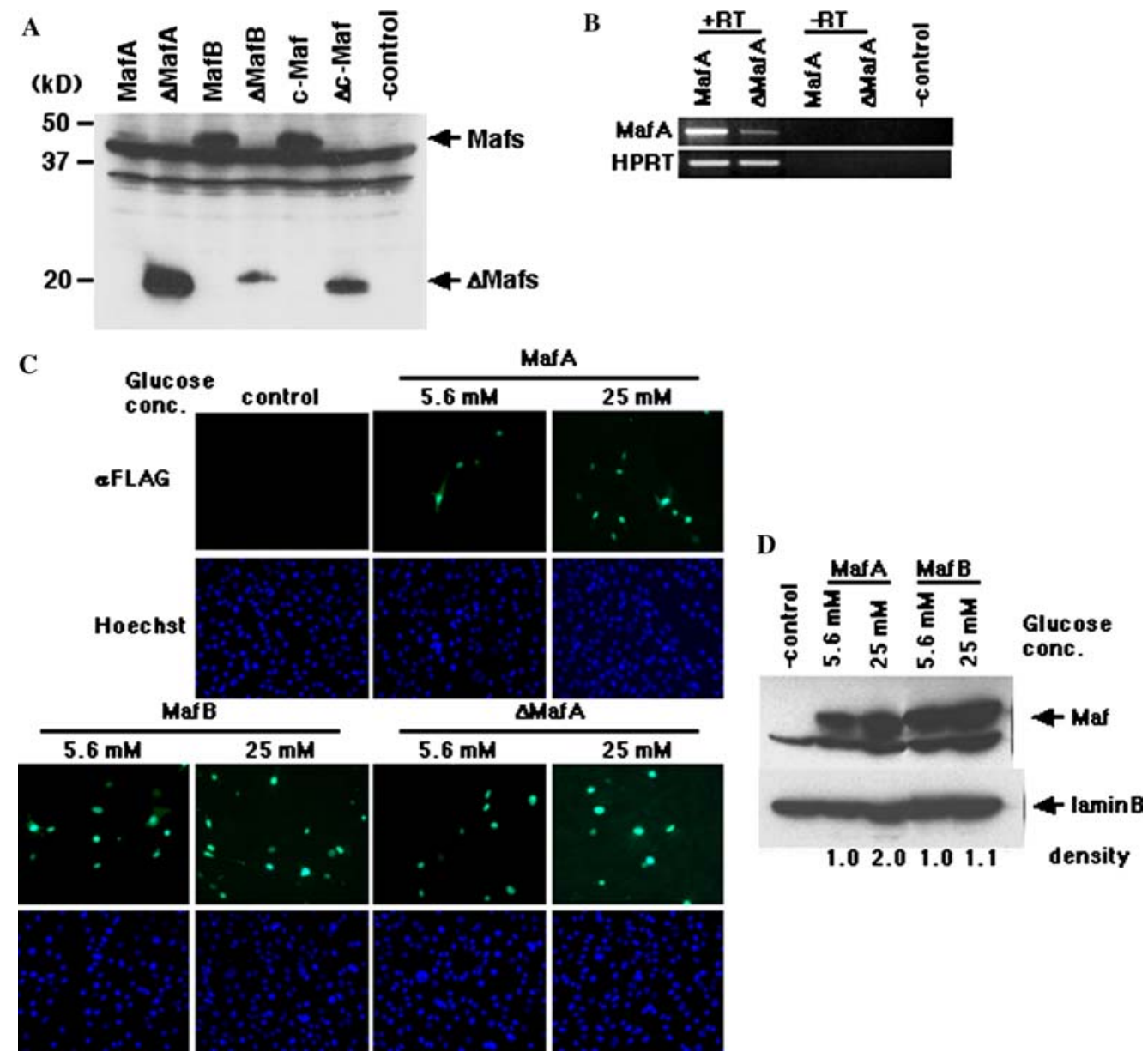

Fig. 9. High glucose state is required for the accumulation of MafA protein. (A) Immunoblot detection of Mafs and $\Delta$ Mafs. Mafs and $\Delta$ Maf expression plasmids were transfected into NIH3T3 cells cultured in normal glucose $(5.6 \mathrm{mM})$ medium. Whole-cell extracts of NIH3T3 were subjected to immunoblot detection by anti-FLAG antibody. (B) Expression levels of MafA and $\triangle$ MafA in the transfected cells cultured in normal glucose medium. MafA and $\triangle$ Maf mRNAs were detected by RT-PCR analysis. (C) Immunostaining of transfected cells. Maf expression plasmids were transfected into NIH3T3 cells. At $24 \mathrm{~h}$ after transfection, normal glucose medium was replaced with high glucose medium ( $25 \mathrm{mM}$ ) for cells in high glucose condition. Then immunostaining at $48 \mathrm{~h}$ after transfection was performed. (D) Immunoblot detection of Maf proteins using transfected NIH3T3 cells. The band density was measured by densitometer (Bio-Rad) and normalized with laminB. The relative value is depicted at the bottom.

by high glucose concentration in vivo, we checked the amount of MafA protein in high glucose condition $(25 \mathrm{mM})$. Immunostaining and Western blot analyses clearly showed that MafA protein was more abundant in high glucose condition than in normal glucose condition $(5.6 \mathrm{mM})$, while that of MafB or $\Delta$ MafA was not changed by glucose concentration (Figs. 9C and D). These results indicated that high glucose state induced the accumulation of MafA protein. Taken together, we concluded that the amount of MafA protein was regulated by glucose concentration, and the acidic domain of MafA protein might be responsible for this regulation.

\section{Discussion}

In this paper, we isolated mouse MafA as the homologue of zebrafish SMaf1. In fact, mouse MafA belongs to the L-Maf/SMaf1 class (Fig. 2C). We showed that mouse MafA transcripts were located in several tissues, using whole mount in situ hybridization (Fig. 3) and RT-PCR analysis (Fig. 4). The MafA mRNA was expressed in mouse somite cells, where the detected level of zebrafish SMaf1 expression was striking [5]. Additionally, the transcripts of zebrafish SMaf1 were also detected in hindbrain cells during zebrafish embryogenesis [5], whereas, in our experiments, the mRNAs of mouse MafA were observed in the developing mouse fetus $(12.5 \mathrm{dpc})$ (Fig. 3). Chicken L-Maf is expressed in the developing lens cells of the chicken embryo, whereas quail MafA, which is almost the same in structure to L-Maf except for one amino acid difference, is expressed in retinal cells [3]. We also detected MafA mRNA in the lens and retina of the mouse embryo (our unpublished observation). These results manifest the various functions of the MafA/LMaf/SMaf1 class of Maf factors in the vertebrate. 
In this study, we indicated that MafA and MafB activate the RIPII and bind to the core site of RIPE3b. Mouse and rat possess two insulin promoters each (insulin promoters I and II), whereas human possesses only one promoter; these insulin promoters have unique transcriptional regulations [33-36]. Two significant differences appeared when the RIPE3b sequences of these insulin promoters were aligned with the MARE sequence (Fig. 8D). One difference was in the human insulin promoter sequence and the other was in the RIPI. Since nucleotide -122 " $C$ " in the human sequence is identical to the one in MARE, although the nucleotide is different from that in other insulin promoters, human RIPE3b seems to be easily activated by Maf transcription factors. On the other hand, nucleotide -130 " $\mathrm{A}$ " in RIPI obviously differs from nucleotide " $G$ " in the other insulin promoters and in the MARE sequence. As we have demonstrated in this paper and as others have reported previously [22,24], "G" is crucial for Maf activity. This difference in the RIPI must be the reason why the Mafs did not activate the RIPI reporter in our experiments. Taken together, we conclude that MafA is not a sufficient transactivator for the RIPI. Furthermore, these data indicate that both the mouse and human insulin promoters contain Maf target sites and can be activated by Maf transcription factors. We have revealed that MafA activates the rat insulin promoter II, but not promoter I. It has been reported that the responses of rat insulin genes to stimulation are different $[33,34]$. Our results imply that, under conditions of stimulation, the difference between rat insulin promoters I and II depends on Maf regulation. It has been reported that mouse insulin promoters I and II are also differentially regulated $[35,36]$. Since the RIPE3b elements of both genes are identical, other elements except for RIPE3b may be responsible for the regulational difference between mouse insulin promoters I and II.

The RIPE3b/C1 element has been identified as one of the most important elements for pancreatic $\beta$-cell specific insulin expression [37-39]. Other important elements are known as E1 and A3 [40-45]. The pancreatic islet restricted transcription factors BETA2/NeuroD and PDX1, which bind to the E1 and A3 elements, have been isolated. Mice deficient in these transcription factors revealed these factors to be indispensable for islet cell development and insulin gene expression [46-49]. In addition, mutations in the BETA2 and PDX1 genes were found in some patients with maturity-onset diabetes of the young (MODY) [50,51]. The RIPE3b has also been shown to be involved in $\beta$-cell-specific insulin gene transcription as well as in its glucose-regulated expression. Previous studies have identified a $\beta$-cell-restricted RIPE3b-binding factor, called the RIPE3b1 activator, that appears in response to glucose in pancreatic $\beta$-cell nuclear extracts [38]. Very recently, two papers have been published stating that the RIPE3b1 activator is MafA [29,30]. Our data confirmed their observations and added new information about RIPE3b recognition by large Maf transcription factors.

It was shown that the transactivation ability of MafA is lower than that of MafB in our system of analysis (Figs. 5,6 and 8). The highest level of transactivation activity of MafA was obtained with $500 \mathrm{ng}$ of effector plasmid (data not shown), and that of MafB was obtained with $100 \mathrm{ng}$ of effector. Since we carried out the transfection assay using $100 \mathrm{ng}$ of effector, MafA activity was not maximal, but that of MafB was. Except for this point, MafA does not contain ample transactivation activity. We also demonstrated that the amount of MafA protein was regulated by glucose concentration (Figs. 9C and D). There are several possible explanations for this result. The most likely possibility is that MafA protein is unstable in the cells, whereas other Mafs are stable in normal glucose condition (Fig. 9A). Recently, it has been published that chicken L-Maf, which is the homologue of mouse MafA, is phosphorylated by FGF/ERK signaling pathways and that phosphorylation of L-Maf induces its degradation [52]. In addition, it has been reported that quail MafA is phosphorylated and its phosphorylation is important for maximum transactivation [53]. These data suggest that mouse MafA must also be phosphorylated and that its phosphorylation may regulate the transcriptional activity and/or stability of MafA by extracellular signaling, glucose. We are now trying to analyze the relationship between the phosphorylation and protein stability of MafA.

In conclusion, we isolated mouse MafA as a homologue of zebrafish SMafl and isolated MafA was expressed in several tissues including pancreatic beta cells. MafA was able to activate transcription from RIPII, but not RIPI, through the RIPE3b element. Further analysis concerning the protein modification and stability of MafA may open up new insights into understanding insulin production and one of the causes of diabetes mellitus.

\section{Acknowledgments}

We thank Dr. T. O'connor for helpful discussions. We are grateful to Drs. T. Moriguchi, S. Kawauchi, and H. Ogino for providing plasmids, Dr. T. Terunuma for technical advice, and M. Hamada and Ms. A. Godo for their excellent assistances. This work was supported in part by Grant-in-Aid from the Ministry of Education, Science, Sports and Culture, the Japanese Society for Promotion of Sciences (RFTF), and Program for Promotion of Basic Research Activities for Innovative Biosciences (PROBRAIN).

\section{References}

[1] M. Nishizawa, K. Kataoka, N. Goto, K.T. Fujiwara, S. Kawai, v-maf, a viral oncogene that encodes a "leucine zipper" motif, Proc. Natl. Acad. Sci. USA 86 (1989) 7711-7715. 
[2] S. Kawai, N. Goto, K. Kataoka, T. Saegusa, H. Shinno-Kohno, M. Nishizawa, Isolation of the avian transforming retrovirus, AS42, carrying the v-maf oncogene and initial characterization of its gene product, Virology 188 (1992) 778-784.

[3] S. Benkhelifa, S. Provot, O. Lecoq, C. Pouponnot, G. Calothy, M.P. Felder-Schmittbuhl, mafA, a novel member of the maf proto-oncogene family, displays developmental regulation and mitogenic capacity in avian neuroretina cells, Oncogene 17 (1998) $247-254$.

[4] H. Ogino, K. Yasuda, Induction of lens differentiation by activation of a bZIP transcription factor, L-Maf, Science 280 (1998) 115-118.

[5] M. Kajihara, S. Kawauchi, M. Kobayashi, H. Ogino, S. Takahashi, K. Yasuda, Isolation, characterization, and expression analysis of zebrafish large Mafs, J. Biochem. 129 (2001) 139-146.

[6] K. Kataoka, K.T. Fujiwara, M. Noda, M. Nishizawa, MafB, a new Maf family transcription activator that can associate with Maf and Fos but not with Jun, Mol. Cell. Biol. 14 (1994) 75817591.

[7] K. Kataoka, M. Nishizawa, S. Kawai, Structure-function analysis of the maf oncogene product, a member of the b-Zip protein family, J. Virol. 67 (1993) 2133-2141.

[8] A. Swaroop, J.Z. Xu, H. Pawar, A. Jackson, C. Skolnick, N. Agarwal, A conserved retina-specific gene encodes a basic motif/ leucine zipper domain, Proc. Natl. Acad. Sci. USA 89 (1992) 266270.

[9] K.T. Fujiwara, K. Kataoka, M. Nishizawa, Two new members of the maf oncogene family, mafK and mafF, encode nuclear b-Zip proteins lacking putative trans-activator domain, Oncogene 8 (1993) 2371-2380

[10] K. Kataoka, K. Igarashi, K. Itoh, K.T. Fujiwara, M. Noda, M. Yamamoto, M. Nishizawa, Small Maf proteins heterodimerize with Fos and may act as competitive repressors of the NF-E2 transcription, Mol. Cell. Biol. 15 (1995) 2180-2190.

[11] S.P. Cordes, G.S. Barsh, The mouse segmentation gene kr encodes a novel basic domain-leucine zipper transcription factor, Cell 79 (1994) 1025-1034.

[12] M. Manzanares, S. Cordes, C.T. Kwan, M.H. Sham, G.S. Barsh, R. Krumlauf, Segmental regulation of Hoxb-3 by kreisler, Nature 387 (1997) 191-195.

[13] M.H. Sieweke, H. Tekotte, J. Frampton, T. Graf, MafB is an interaction partner and repressor of Ets-1 that inhibits erythroid differentiation, Cell 85 (1996) 49-60.

[14] V.S. Sadl, F. Jin, J. Yu, S. Cui, D. Holmyard, S.E. Quaggin, G.S. Barsh, S.P. Cordes, The mouse kreisler (Krml1/MafB) segmentation gene is required for differentiation of glomerular visceral epithelial cells, Dev. Biol. 249 (2002) 16-29.

[15] C. Kurschner, J.I. Morgan, The maf proto-oncogene stimulates transcription from multiple sites in a promoter that directs Purkinje neuron-specific gene expression, Mol. Cell. Biol. 15 (1995) 246-254.

[16] I.C. Ho, M.R. Hodge, J.W. Rooney, L.H. Glimcher, The protooncogene c-maf is responsible for tissue-specific expression of interleukin-4, Cell 85 (1996) 973-983.

[17] S. Kawauchi, S. Takahashi, O. Nakajima, H. Ogino, M. Morita, M. Nishizawa, K. Yasuda, M. Yamamoto, Regulation of lens fiber cell differentiation by transcription factor c-Maf, J. Biol. Chem. 274 (1999) 19254-19260.

[18] R.V. Jamieson, R. Perveen, B. Kerr, M. Carette, J. Yardley, E. Heon, M.G. Wirth, V. van Heyningen, D. Donnai, F. Munier, G.C.M. Black, Domain disruption and mutation of the bZIP transcription factor, MAF, associated with cataract, ocular anterior segment dysgenesis and coloboma, Hum. Mol. Genet. 11 (2002) 33-42.

[19] Q. Farjo, A. Jackson, S. Pieke-Dahl, K. Scott, W.J. Kimberling, P.A. Sieving, J.E. Richards, A. Swaroop, bZIP transcription factor gene NRL: structure, genomic sequence, and fine linkage mapping at 14q11.2 and negative mutation analysis in patients with retinal degeneration, Genomics 45 (1997) 395-401.

[20] Q. Liu, X. Ji, M.L. Breitman, P.F. Hitchcock, A. Swaroop, Expression of the bZIP transcription factor gene $\mathrm{Nrl}$ in the developing nervous system, Oncogene 12 (1996) 207-211.

[21] A. Rehemtulla, R. Warwar, R. Kumar, X. Ji, D.J. Zack, A. Swaroop, The basic motif-leucine zipper transcription factor $\mathrm{Nrl}$ can positively regulate rhodopsin gene expression, Proc. Natl. Acad. Sci. USA 93 (1996) 191-195.

[22] K. Kataoka, M. Noda, M. Nishizawa, Maf nuclear oncoprotein recognizes sequences related to an AP-1 site and forms heterodimers with both Fos and Jun, Mol. Cell. Biol. 14 (1994) 700-712.

[23] T.K. Kerppola, T. Curran, Maf and Nrl can bind to AP-1 sites and form heterodimers with Fos and Jun, Oncogene 9 (1994) 675684.

[24] T.K. Kerppola, T. Curran, A conserved region adjacent to the basic domain is required for recognition of an extended DNA binding site by Maf/Nrl family proteins, Oncogene 9 (1994) 3149-3158.

[25] I. Matsuo, K. Yasuda, The cooperative interaction between two motifs of an enhancer element of the chicken alpha A-crystallin gene, alpha CE1 and alpha CE2, confers lens-specific expression, Nucleic Acid Res. 20 (1992) 3701-3712.

[26] R. Kumar, S. Chen, D. Scheurer, O.L. Wang, E. Duh, C.H. Sung, A. Rehemtulla, A. Swaroop, R. Adler, D.J. Zack, The bZIP transcription factor $\mathrm{Nrl}$ stimulates rhodopsin promoter activity in primary retinal cell cultures, J. Biol. Chem. 271 (1996) 2961229618.

[27] C.B. Moens, S.P. Cordes, M.W. Giorgianni, G.S. Barsh, C.B. Kimmel, Equivalence in the genetic control of hindbrain segmentation in fish and mouse, Development 125 (1998) 381-391.

[28] M. Schvarzstein, A. Kirn, P. Haffter, S.P. Cordes, Expression of Zkrml2, a homologue of the Krml1/val segmentation gene, during embryonic patterning of the zebrafish (Danio rerio), Mech. Dev. 80 (1999) 223-226.

[29] M. Olbrot, J. Rud, L.G. Moss, A. Sharma, Identification of b-cellspecific insulin gene transcription factor RIPE3b1 as mammalian MafA, Proc. Natl. Acad. Sci. USA 99 (2002) 6737-6742.

[30] K. Kataoka, S. Han, S. Shioda, M. Hirai, M. Nishizawa, H. Handa, MafA is a glucose-regulated and pancreatic b-cell-specific transcriptional activator for the insulin gene, J. Biol. Chem. 277 (2002) 49903-49910.

[31] K. Tomita, K. Moriyoshi, S. Nakanishi, F. Guillemot, R. Kageyama, Mammalian achaute-scute and atonal homologs regulate neuronal versus glial fate determination in the central nervous system, EMBO J. 19 (2000) 5460-5472.

[32] Y. Katoh, K. Itoh, E. Yoshida, M. Miyagishi, A. Fukamizu, M. Yamamoto, Two domains of Nrf2 cooperatively bind CBP, a CREB binding protein, and synergistically activate transcription, Genes Cell 6 (2001) 857-868.

[33] Z. Ling, H. Heimberg, A. Foriers, F. Scuit, D. Pipeleers, Differential expression of rat insulin I and II messenger ribonucleic acid after prolonged exposure of islet b-cell to elevated glucose levels, Endocrinology 139 (1998) 491-495.

[34] K. Kakita, S. Giddings, M.A. Permutt, Biosynthesis of rat insulins I and II: evidence for differential expression of the two genes, Proc. Natl. Acad. Sci. USA 79 (1982) 2803-2807.

[35] B.M. Wentworth, C. Rhodes, B. Schnetzler, D.J. Gross, P.A. Halban, L. Villa-Komaroff, The ratio of mouse insulin I: insulin II does not reflect that of the corresponding preproinsulin mRNAs, Mol. Cell. End. 86 (1992) 177-186.

[36] L. Deltour, P. Leduque, N. Blume, O. Madsen, P. Dubois, J. Jami, D. Bucchini, Differential expression of the two nonallelic proinsulin genes in the developing mouse embryo, Proc. Natl. Acad. Sci. USA 90 (1993) 527-531.

[37] Y.P. Hwung, Y.Z. Gu, M.J. Tsai, Cooperativity of sequence elements mediates tissue specificity of the rat insulin II gene, Mol. Cell. Biol. 10 (1990) 1784-1788. 
[38] S.Y. Sieh, M.J. Tsai, Cell-specific and ubiquitous factors are responsible for the enhancer activity of the rat insulin II gene, J. Biol. Chem. 266 (1991) 16708-16714.

[39] A. Sharma, R. Stein, Glucose-induced transcription of the insulin gene is mediated by factors required for beta-cell-type-specific expression, Mol. Cell. Biol. 14 (1994) 871-879.

[40] T. Edlund, M.D. Walker, P.J. Barr, W.J. Rutter, Cell-specific expression of the rat insulin gene: evidence for role of two distinct 5 flanking element, Science 230 (1985) 912-916.

[41] O. Karlsson, T. Edlund, J.B. Moss, W.J. Rutter, M.D. Walker, A mutational analysis of the insulin gene transcription control region: expression in beta cells is dependent on two related sequences within the enhancer, Proc. Natl. Acad. Sci. USA 84 (1987) 8819-8823.

[42] D.T. Crowe, M.J. Tsai, Mutagenesis of the rat insulin II $5^{\prime}$ flanking region defines sequences important for expression in HIT cells, Mol. Cell. Biol. 9 (1989) 1784-1789.

[43] J. Whelan, S.R. Cordle, E. Henderson, P.A. Weil, R. Stein, Identification of a pancreatic beta-cell insulin gene transcription factor that binds to and appears to activate cell-type-specific expression: its possible relationship to other cellular factors that bind to a common insulin gene sequence, Mol. Cell. Biol. 10 (1990) 1564-1572.

[44] M.S. German, J. Wang, R.B. Chadwick, W.J. Rutter, Synergistic activation of the insulin gene by a LIM-homeo domain protein and a basic helix-loop-helix protein: building a functional insulin minienhancer complex, Genes Dev. 6 (1992) 2165-2176.

[45] M. Peshavaria, L. Gamer, E. Hendersn, G. Teitelman, C.V.E. Wright, R. Stein, XIHbox, An endoderm-specific Xenopus homeodomain protein, is closely related to a mammalian insulin gene transcription factor, Mol. Endocrinol. 8 (1994) 806-816.
[46] F.J. Naya, C.M. Stellrecht, M.J. Tsai, Tissue-specific regulation of the insulin gene by a novel basic helix-loop-helix transcription factor, Genes Dev. 9 (1995) 1009-1019.

[47] F.J. Naya, H.P. Huang, Y. Qiu, H. Mutoh, F.J. DeMayo, A.B. Leiter, M.J. Tsai, Diabetes, defective pancreatic morphogenesis, and abnormal enteroendocrine differentiation in BETA2/NeuroDdeficient mice, Genes Dev. 11 (1997) 2323-2334.

[48] H. Ohlsson, K. Karlsson, T. Edlund, IPF1, a homeodomaincontaining transactivator of the insulin gene, EMBO J. 12 (1993) 4251-4259.

[49] H.V. Petersen, P. Serup, J. Leonard, B.K. Michelsen, O.D. Madsen, Transcriptional regulation of the human insulin gene is dependent on the homeodomain protein STF1/IPF1 acting through the CT boxes, Proc. Natl. Acad. Sci. USA 91 (1994) 10465-10469.

[50] S.Y. Kristinsson, E.T. Thorolfsdottir, B. Talseth, E. Steingrimsson, A.V. Throsson, T. Helgason, A.B. Hreidarsson, R. Arngrimsson, MODY in Iceland is associated with mutations in HNF-1 alpha and a novel mutation in NeuroD1, Diabetologia 44 (2001) 2098-2103.

[51] D. Melloul, A. Tsur, D. Zangen, Pancreatic duodenal Homeobox (PDX-1) in health and disease, J. Pediatr. Endocrinol. Metab. 15 (2002) 1461-1472.

[52] H. Ochi, Y. Kageyama, K. Yasuda, The stability of the lens-specific Maf protein is regulated by FGF/ERK signaling in lens fiber differentiation, J. Biol. Chem. 237 (2002) 537544.

[53] S. Benkhelifa, S. Provot, E. Nabais, A. Eychene, G. Calothy, M.P. Felder-Schmittbuhl, Phosphorylation of MafA is essential for its transcriptional and biological properties, Mol. Cell. Biol. 21 (2001) 4441-4452. 